\title{
Resistance for Anti-Tuberculosis Drugs in Central Black Sea Region of Turkey
}

\author{
SALIH BILGIN $^{1}$, MEFTUN UNSAL $^{2 *}$, HASAN HAMZA CEBI ${ }^{1}$ and ALPER AKGUNES ${ }^{1}$ \\ ${ }^{1}$ Samsun Chest Diseases and Chest Surgery Hospital \\ ${ }^{2}$ Ondokuz Mayýs University, Faculty of Medicine, Department of Chest Diseases, Samsun, Turkey
}

Received 2010, revised 2010, accepted 2010

\begin{abstract}
One of the primary aims in tuberculosis (TB) management is to detect new cases as early as possible, and instigate the most appropriate therapy, for which it is important to know the characteristics of TB drug resistance in society. The aim of our study was to determine the resistance status of tuberculosis in the Samsun region of Turkey. To achieve that, the medical records of 1,029 pulmonary tuberculosis patients admitted to Samsun Chest Diseases and Chest Surgery Hospital between 2004 and 2006 were analyzed for drug resistance characteristics. In order to define the problem, isolates were tested on Lowenstein-Jensen medium. For drug susceptibility testing, isoniazid (I), streptomycin (S), ethambutol (E), rifampicin (R) and the radiometric Bactec $460 \mathrm{~TB}$ system were used. Eighty-six percent (86\%) of the cases (623/721) were new patients, and $13.5 \%$ (98/721) were previously treated cases. One hundred and thirty-four (134) of the 721 patients $(18.6 \%)$ had resistance to one or more drugs. Resistance to any drug was determined in $16.9 \%(105 / 623)$ cases of new patients. I resistance was $13.2 \%$, any R resistance was $2.9 \%$, and multi-drug resistance (MDR) was $1.9 \%$. In previously treated cases, resistance to any drug was $29.6 \%$, any I resistance was $26.5 \%$, any R resistance was $15.3 \%$, and MDR was $13.3 \%$. It was concluded that resistance to anti-tuberculosis drugs is an important problem in Samsun.
\end{abstract}

K e y w ords: anti-tuberculosis drugs, drug resistance, tuberculosis

\section{Introduction}

Tuberculosis is still an important health problem around the world. In 2008, 2.7 million of 5.7 million new cases worldwide were smear-positive (World Health Organization, 2009). TB is one of the oldest known diseases and despite recent progress in global control efforts (Mc Cray et al., 1997), resistance to anti-tuberculosis drugs is a problem that has arisen within the chemotherapy era. Drug resistance, which is one of the important factors working against the control of tuberculosis infection in society, is a manmade phenomenon. The use of drugs in suitable doses and duration can control the illness to a great extent. However, inadequate treatment, due to poor patient compliance; inappropriate therapy regimens and inadequate drug supplies, are important factors in the development of drug resistance (Mahmoudi et al., 1993).

There is considerable variation in the incidence of anti-tuberculosis drug resistance, and major differences exist worldwide. In order to optimize standard anti-tuberculosis drug therapy, and to increase the success of control programs, it is important to know drug resistance patterns in a society (Espinal, 2003). The aim of this study was to ascertain resistance levels for anti-tuberculosis drugs in the central Black Sea region of Turkey.

\section{Experimental}

\section{Material and Methods}

The medical records and and drug resistance characteristics of 1029 pulmonary tuberculosis patients diagnosed at the Samsun Chest Diseases and Chest Surgery Hospital in Samsun, Turkey between 2004 and 2006 were analyzed retrospectively. According to World Health Organization (WHO) guidelines, drug resistance in cases of new patients was defined as the presence of resistant Mycobacterium tuberculosis isolates in newly diagnosed patients who had never been treated with anti-tuberculosis drugs or had been treated for less than 1 month. Drug resistance

* Corresponding author: Meftun Unsal, Atatürk Bulvari Körfez mah.Ondokuz Mayis Üniversitesi Lojmanlari G Blok. No: 23 Samsun-Turkey; phone: +0903624381333; fax: +0903624576041; e-mail: meftununsal@gmail.com 
among previously treated patients was defined as resistance found in patients with a history of a least one month of anti-tuberculosis therapy. Multidrug resistance was defined as resistance to at least isoniazid and rifampicin (WHO).

Sputum and culture analysis tests were performed in the Samsun Hospital Chest Diseases Bacteriology laboratory. (The specimens in this study consisted of sputum samples only.) Cultures were done using the radiometric Bactec 460 TB system (Becton Dickinson, USA) and Lowenstein-Jensen (LJ) medium (Biomeriux, France). Susceptibility was tested with the radiometric Bactec 460 TB method (isoniazid $0.2 \mu \mathrm{g} / \mathrm{ml}$, streptomycin $2.0 \mu \mathrm{g} / \mathrm{ml}$, ethambutol $2.5 \mu \mathrm{g} / \mathrm{ml}$ and rifampicin $2.0 \mu \mathrm{g} / \mathrm{ml}$ ), as well as by the proportion method on solid medium. Resistance was defined according to standard protocols (Siddiqi, 1996). If more than one susceptibility test was performed per patient per year, the results of the initial test were included in the evaluation. Statistical analyses were done using SPSS (SPSS Inc., Chicago, Ill., USA) software.

\section{Results}

The total number of TB patients included in this study was 1029. Seven hundred and twenty one $(79.0 \%)$ were culture-positive. Five hundred and forty seven were male, and 147 were female. Mean age was $41.5 \pm 15.4$ years (range 14-88); mean female age was 37.6 \pm 19.1 years (range 14-83); and mean male age was $41.5 \pm 15.4$ years (range 14-88). All the patients were born in Turkey and were HIV negative. There were $70.6 \%$ of positive cultures $(623 / 883)$ in new patients and $67.1 \%(98 / 146)$ in previously treated cases (Table I).

Among 623 culture positive new patients, the resistance ratio for one or more drugs was $16.9 \%$ $(105 / 623)$. In previously treated cases, resistance to any drug was $29.6 \%$ (29/98) (Table II).

Resistance to one, two, three and four drugs was observed in $92(12.7 \%), 32(4.4 \%), 8(1.1 \%)$ and $2(0.3 \%)$ patients, respectively. Single drug resistance was most commonly seen with I (66 patients, 9.2\%),

Table I

Characteristics of cultures and smears of TB patients at the Samsun Chest Diseases and Chest Surgery Hospital from 2004 to 2006.

\begin{tabular}{|l|c|c|c|c|c|}
\hline \multicolumn{1}{|c|}{ Patients } & $\begin{array}{c}\text { Acid-fast } \\
\text { bacilli positive }\end{array}$ & $\begin{array}{c}\text { Acid-fast } \\
\text { bacilli negative }\end{array}$ & Culture positive & Culture negative & Total \\
\hline New Patients & $550(62.3 \%)$ & $333(37.7 \%)$ & $623(70.6 \%)$ & $260(29.4 \%)$ & $883(100.0 \%)$ \\
\hline Previously treated cases & $91(62.3 \%)$ & $55(37.7 \%)$ & $98(67.1 \%)$ & $48(32.9 \%)$ & $146(100.0 \%)$ \\
\hline Total & $641(62.3 \%)$ & $388(37.7 \%)$ & $721(79.0 \%)$ & $308(29.9 \%)$ & $1029(100.0 \%)$ \\
\hline \multicolumn{7}{|r|}{$X 2=0.00, p=0.992$} & \multicolumn{2}{|c|}{ X2 $=0.70, \mathrm{p}=0.402$} & \\
\hline
\end{tabular}

Table II

Drug resistance ratios

\begin{tabular}{|l|c|c|c|}
\hline \multicolumn{1}{|c|}{ Patients } & $\begin{array}{c}\text { Sensitive } \\
\text { to all drugs }\end{array}$ & $\begin{array}{c}\text { Resistant to one } \\
\text { or more drugs }\end{array}$ & Total (n) \\
\hline New Patients & $518(83.1 \%)$ & $105(16.9 \%)$ & $623(100.0 \%)$ \\
\hline Previously treated cases & $69(70.4 \%)$ & $29(29.6 \%)$ & $98(100.0 \%)$ \\
\hline Total & $587(81.4 \%)$ & $134(18.6 \%)$ & $721(100.0 \%)$ \\
\hline & \multicolumn{2}{|c|}{$\mathrm{X} 2=9.1, \mathrm{p}=0.003$} & \\
\hline
\end{tabular}

Table III

Single Drug Resistance Ratios

\begin{tabular}{|l|c|c|c|c|c|c|c|c|c|c|c|}
\hline \multirow{3}{*}{ Patients } & \multicolumn{4}{|c|}{ One Drug } & \multicolumn{3}{c|}{ Two Drugs } & \multicolumn{3}{c|}{ Three Drugs } & Four Drugs \\
\cline { 2 - 13 } & $\begin{array}{c}\mathrm{I} \\
\mathrm{n}(\%)\end{array}$ & $\begin{array}{c}\mathrm{R} \\
\mathrm{n}(\%)\end{array}$ & $\begin{array}{c}\mathrm{S} \\
\mathrm{n}(\%)\end{array}$ & $\begin{array}{c}\mathrm{E} \\
\mathrm{n}(\%)\end{array}$ & $\begin{array}{c}\mathrm{I}+\mathrm{E} \\
\mathrm{n}(\%)\end{array}$ & $\begin{array}{c}\mathrm{I}+\mathrm{S} \\
\mathrm{n}(\%)\end{array}$ & $\begin{array}{c}\mathrm{I}+\mathrm{R} \\
\mathrm{n}(\%)\end{array}$ & $\begin{array}{c}\mathrm{I}+\mathrm{R}+\mathrm{E} \\
\mathrm{n}(\%)\end{array}$ & $\begin{array}{c}\mathrm{I}+\mathrm{S}+\mathrm{E} \\
\mathrm{n}(\%)\end{array}$ & $\begin{array}{c}\mathrm{I}+\mathrm{R}+\mathrm{S} \\
\mathrm{n}(\%)\end{array}$ & $\begin{array}{c}\mathrm{I}+\mathrm{S}+\mathrm{R}+\mathrm{E} \\
\mathrm{n}(\%)\end{array}$ \\
\hline New Patients & $54(8.6)$ & $6(0.9)$ & $108(1.6)$ & $7(1.1)$ & $4(0.6)$ & $10(1.6)$ & $9(1.4)$ & $2(0.3)$ & $2(0.3)$ & $1(0.1)$ & 0 \\
\hline $\begin{array}{l}\text { Previously } \\
\text { treated cases }\end{array}$ & $12(12.2)$ & $2(2.0)$ & 0 & $1(15.3)$ & 0 & $1(1)$ & $8(8.1)$ & $2(2)$ & 0 & $1(0.1)$ & $2(2)$ \\
\hline Total & $66(9.1)$ & $8(1.1)$ & $10(1.3)$ & $8(1.1)$ & $4(0.5)$ & $11(1.5)$ & $17(2.3)$ & $4(0.5)$ & $2(0.3)$ & $2(0.3)$ & $2(1.5)$ \\
\hline \multicolumn{4}{|c|}{$92(68.6 \%)$} & \multicolumn{3}{|c|}{$32(23.9 \%)$} & & $8(6.0 \%)$ & $2(1.5 \%)$ \\
\hline
\end{tabular}

I - isoniazid; R - rifampicin; S - streptomycin; E - ethambutol 
Table IV

Resistance to drugs

\begin{tabular}{|l|c|c|c|c|}
\hline \multicolumn{1}{|c|}{ Patients } & Isoniazid & Rifampicin & Streptomycin & Ethambutol \\
\hline New Patients & $82 / 623(13.2 \%)$ & $18 / 623(2.9 \%)$ & $23 / 623(3.7 \%)$ & $15 / 623(2.4 \%)$ \\
\hline Previously treated cases & $26 / 98(26.5 \%)$ & $15 / 98(15.3 \%)$ & $4 / 98(4.1 \%)$ & $5 / 98(5.1 \%)$ \\
\hline Total & $108 / 721(14.9 \%)$ & $33 / 721(4.6 \%)$ & $27 / 721(3.7 \%)$ & $20 / 721(2.8 \%)$ \\
\hline
\end{tabular}

followed by S (10 patients, $1.4 \%)$, R (8 patients, $1.1 \%)$ and $\mathrm{E}$ (8 patients, $1.1 \%$ ) (Table III).

Total cumulative resistance ratios were $14.9 \%$ for I, $4.6 \%$ for R, $3.7 \%$ for $\mathrm{S}$ and $2.8 \%$ for E (Table IV).

Total initial resistance to I was $8.7 \%(54 / 623)$ and acquired resistance was $12.2 \%$ (26/98). Multi-drug resistance (MDR), which was deemed to be resistance to at least I and R, was $1.9 \%(12 / 623)$ and $13.3 \%$ $(13 / 98)$ in new cases and previously treated cases, respectively $(\mathrm{X} 2=32.5, \mathrm{p}=0.0000)$.

\section{Discussion}

The prevalence of drug resistance to Mycobacterium tuberculosis shows marked geographic differences, and is the key to determining the drugs chosen for the initial treatment of tuberculosis. The surveillance of drug resistance is an essential tool for monitoring the effectiveness of tuberculosis control programs and, through policy development, for improving national and global TB control (Liu et al., 2004; Bastian et al., 1999). Poorly planned or badly implemented tuberculosis control programs, if the prevalence is high in these regions in particular, cause a rapid increase in drug resistance. However, in countries such as China and India where tuberculosis control programs have been carried out well, though the prevalence is high, drug resistance is low (Cohn et al., 1997).

The Global Project on Anti-tuberculosis Drug Resistance Surveillance, which included 138 locations or countries between 1994 and 2007, revealed that the median prevalence of drug resistance was $2.9 \%$ among new cases and $15.3 \%$ among previously treated cases (World Health Organization, 2008).

In Turkey, there have been meta-analyses done on the basis of regional data from state and university hospitals that compiled their own results (Senol et al., 2005; Bengisun et al., 2000; Uçan et al., 1994; Ang and Uzun, 1998; Yolsal et al., 1998). There had been no national study on resistance results for all of Turkey until 2005, when data obtained from patient records in the Tuberculosis Dispensary were reported. The National Turkey TB Surveillance Report of 2005 revealed that resistance among new cases was $14.4 \%$, and in a previous report was $34.8 \%$ (Gumuslu et al., 2007). However, the data in that report were only from dispensary records and did not include patient records in hospitals. It is therefore debatable whether it is reasonable to compare those data with previous data (Karagoz et al., 2008). In a regional study done recently, it was revealed that resistance to at least one drug was $3.2 \%$ in new cases, and $13.5 \%$ in previously treated cases (Karagoz et al., 2008). Samsun, a province situated in the central Black Sea Region of Turkey, has a population of approximately 1210000 . Samsun Chest Diseases Hospital, which has 180 beds, may be considered a reference hospital. There have been no previous studies of resistance to anti-tuberculosis drugs in this region. In a study done by Arseven et al in the eastern Black Sea Region in 1995, it was determined that primary resistance to any one antituberculosis drug was $24.8 \%$ and that secondary resistance was $47.8 \%$ (Arseven et al., 1995).

In the present study, resistance to any drug was found in $105(16.9 \%)$ of 623 new patients. In previously treated cases, resistance to any drug was found in 29 (29.6\%) patients. Any I resistance was the most common drug resistance in both new and previously treated cases (new: 13.2\%; previously treated: $26.5 \%$ ). These results were higher than the resistance documented for the same drug in new cases and lower than in previously treated cases reported under Global Surveillance (new: $10.3 \%$; previously treated: $27.7 \%$ ).

Resistance to one drug was the most common drug resistance situation in new cases and previously treated cases, with $12.3 \%$ and $15.3 \%$, respectively. Single I resistance was the most common single resistance, both in new and previously treated cases. Single $\mathrm{S}$ resistance was not detected in previously treated cases. In combined resistance, the highest resistance was for I $(14.9 \%)$. It was followed by $\mathrm{R}(4.6 \%)$, $\mathrm{S}(3.7 \%)$ and $\mathrm{E}(2.8 \%)$. In Turkey in 2007, I (11.5\%), $\mathrm{S}(8.1 \%), \mathrm{R}(21.1 \%)$ and $\mathrm{E}(4 \%)$ were reported (Gumuslu et al., 2007).

Since the most potent bactericidal effect on isoniazid is in the early phase of treatment, resistance to this drug is an important indicator of drug resistant TB. I resistant strains may also develop resistance to $\mathrm{R}$ and thus acquire multi-drug resistance. An increased risk of treatment failure has also been demonstrated in areas with high levels of I resistance (Storla et al., 2007). Therefore, our results for I resistance may be an indicator as to how to manage drug resistance treatment in our region.

Each year, 400,000 people develop MDR-TB, a form of TB that does not respond to the standard 
treatment (World Health Organization, 2008). It was estimated in 2006 that resistance among all cases globally was $4.8 \%$. MDR in new cases was $3.1 \%$ and in previously treated cases was $19.3 \%$. MDR has increased in certain countries such as Korea and Peru, and decreased in such countries as the USA and China. It has been relatively stable in Baltic countries such as Estonia, Latvia and Lithuania. MDR resistance in these countries was $4.4 \%, 1.6 \%$ and $20.3 \%$, respectively (World Health Organization, 2008).

The most important problem in drug resistance is multi-drug resistance (MDR). MDR is higher in countries with sub-standard national tuberculosis programs or in lower socio-economic groups. It is a consequence of inadequate therapy, insufficient drug use or noncompliance by the patient (Senol et al., 2005; Bengisun et al., 2000). Therapy success is inherently lower in these cases.

In Turkey, according to the 2005 National Turkey TB Surveillance Report, MDR resistance was 3.1\% in new cases and $5.1 \%$ in previously treated cases.

In our study, MDR levels were $1.9 \%$ in new cases and $13.3 \%$ in previously treated cases. Our MDR results in new cases were lower than for Turkey previously and internationally. For previously treated cases, our results were higher than for other studies from Turkey, and lower than those internationally.

There have been studies showing resistance ratios over the years. Different results may stem from the use of different anti-tuberculosis treatments, the number of the cases used in the study, and/or absence of reference laboratories.

In 2003, Direct Observed Therapy (DOTS) began in some pilot regions, including Samsun. However, there has not been a study showing the results of DOTS treatment in this region. In addition, not all doctors and institutions have used DOTS treatment. Therefore, it is not possible to objectively discuss the effects of DOTS on the results of our study.

In retrospect, the limitations of our study were as follows: there was no data available from previous years, and our laboratory methods were different from the ones used in other studies.

For future action, the following strategies have been proposed by WHO for Turkey (Organization, W.H.O. 2007): 1. Starting an MDR-TB pilot project; 2. Strengthening national laboratory resources and processes; 3. Implementing MDR-TB internationally agreed infection control measures.

These three strategies should be implemented and the necessary studies initiated as a high priority. As a first step, urgent measures to control the spread of tuberculosis and prevent increased drug resistance should be taken. In parallel, data should be obtained systematically across Turkey in order to understand the dimensions of the problem nationally.
Acknowledgment

The authors thank Gregory Thomas Sullivan of OYDEM at Ondokuz Mayis University in Samsun, Turkey for editing in English an earlier version of this manuscript.

\section{Literature}

Ang Ö and M. Uzun. 1998. Latest situation of tuberculosis in Turkey. J. Klimik 11(1): 3-5.

Arseven O., H. Eraksoy, Y. Uzun, C. Sepkin, A. Kalayciolu, M. Özmenoğlu and O. Bölükbaşı. 1995. Antituberculosis drug resistance in the eastern Black sea Region of Turkey (in Turkish). J. Klimik 8: 63-67

Bastian I. and R. Colebunders. 1999. Treatment and prevention of multidrug - resistant tuberculosis. Drugs 58: 633-616.

Bengisun S.J., D. Karnak, I. Palabiyikodlu and N. Saygun. 2000. Mycobacterium tuberculosis drug resistance in Turkey, 1976-97, 1976-97. Scand. J. Infect. Dis. 32: 507-510.

Cohn D.L., F. Bustreo and M.C. Raviglione. 1997. Drug-resistant tuberculosis: review of the worldwide situation and the WHO/ IUATLD Global Surveillance Project. International Union Against Tuberculosis and Lung Disease. Clin. Infect. Dis. 24 Suppl 1: S121-30.

Liu C.E., C.H. Chen CH, Hsiao, T.G. Young, R.W. Tsay and C.P. Fung. 2004. Drug resistance of Mycobacterium tuberculosis complex in central Taiwan. J. Microbiol. Immunol. Infect. 37: 295-300.

Espinal M.A. 2003. The global situation of MDR-TB. Tuberculosis (Edinb). 83: 44-51.

Gumuslu F., S. Ozkara, S. Ozkan, F. Baykal and U. Gullu. 2007. TB Management report in Turkey (in Turkish). Ankara, Turkey: Department of Tuberculosis Control Ministry of Health. Karagoz T, P. Pazarli, O.Y. Mocin, D. Duman, G. Duman, C. Salturk and O. Unal. 2008. Evaluation of drug resistance in pulmonary tuberculosis patients at Sureyyapasa Chest Diseases Hospital, Istanbul, Turkey. The International Journal of Tuberculosis and Lung Disease 12: 631-635.

Mahmoudi A. and M.D. Iseman. 1993. Pitfalls in the care of patients with tuberculosis. Common errors and their association with the acquisition of drug resistance. JAMA 270: 65-68.

Mc Cray E., C. Weinbaum and C.R. Braden. 1997. The epidemiology of tuberculosis in the United States. Clin. Chest Med. 18: 99-113.

Senol G., B. Komurcuoglu and A. Komurcuoglu. 2005. Drug resistance of Mycobacterium tuberculosis in Western Turkey: a retrospective study from 1100-bed teaching hospital. J. Infect. 50: 306-311.

Siddiqi SH. 1996. Drug susceptibility testing. In: BACTEC TB system product and procedure manual (Revision E). Maryland: BectonDickinson, pp. IV.1-IV.23

Storla D.G., Z. Rahim, M.A. Islam, S. Plettner, V. Begum, B. Myrvang, G. Bjune, E. Rønnild, U.R. Dahle and T. Mannsaker. 2007. Drug resistance of Mycobacterium tuberculosis in the Sunamganj District of Bangladesh. Scand. J. Infect. Dis. 39: 142-145.

Uçan E.S. 1994. Problem of anti-tuberculosis drug resistance in Turkey. J. Tuberc. Toraks 42: 219-225.

World Health Organization. 2008. Anti-tuberculosis drug resistance in the world: the WHO/IUATLD Global Project on AntiTuberculosis Drug Resistance Surveillance. WHO/TB, Geneva. W.H.O. Organization. 2007. The Global MDR-TB \& XDR-TB response Plan 2007-2008. World.Health Organization Document. WHO/HTM/TB/2007.387.

Yolsal N., G. Malat, R. Dişçi, M. Orkun and Z. Kılçaslan. 1998. Comparison of tuberculosis drugs resistance problem in years 1984-99 and 1999-94 in years in Turkey. Meta analyze. J. Klimik 11: 6-9. 